\title{
Assessing the impact of emerging technologies on the Australian Army
}

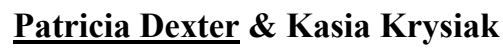 \\ ${ }^{a}$ Joint \& Operations Analysis Division, Defence Science \& Technology Organisation \\ Email: patricia.dexter@dsto.defence.gov.au
}

\begin{abstract}
The relationship between emerging technologies and how the Army conducts its business is not a simple one. Army has a requirement for plausible emerging technology impact information in order to provide guidance for strategic planning and future development across the Army. An earlier study assessing emerging technologies on Army force structure highlighted the need for an ongoing program of work. In order to generate an ongoing program of traceable and consistent emerging technology information a process was developed which would support the nature of this work based upon the requirements of the Australian Army.

This project leverages off the emerging technologies work already conducted within DSTO, and couples with ongoing research and techniques that are well developed to produce an evolutionary ongoing process. An Army centric focus is used for analysis of plausible impacts of emerging technologies on generic Army functions over a rolling 30 year timeframe. In order to undertake this, a well-defined and consistent framework was required which would provide a common language to underpin the entire process. This framework was developed as a two-sided classification framework of emerging technology categories on one axis and generic functions of the Australian Army on the other. Using a framework of this nature has some limitations in that there are technologies which map into multiple categories; however it was found that this limitation was easily managed against the benefits provided by the ability of this framework to allow this complex space to be structured for study. The classification framework is presented as the first item in this paper.

The determination of plausible impacts of emerging technologies on the Australian Army is undertaken using a well-established qualitative technique called TOWS (Threats, Opportunities, Weaknesses and Strengths) which is designed to deduce outcomes and strategies from the combinations of these elements. TOWS is reliant on the strength and breadth of the Subject Matter Experts consulted and the ability of these experts and the analytical team to develop the outcomes/strategies and impacts. This plausible impact determination is the second focus of this paper, where the use of the TOWS method (as part of the larger emerging technology evaluation process) is presented with a sample of an impact analysis.
\end{abstract}

The plausible impact outcomes from this analytical process provide the Army with documented and researched outcomes and strategies resulting from the consideration of technology areas on Army functions, which may have impact on the way the Army conducts these functions in the future. These outcomes and strategies are provided to the Army for consideration as a part of their future strategic planning and development process. They cover the breadth of the external threats and opportunities as well as internal weaknesses and strengths for plausible technology impact on Army function and where the risk or opportunity may lie.

Keywords: TOWS, impact analysis, emerging technology 


\section{TWO-SIDED CLASSIFICATION FRAMEWORK}

A classification framework was needed as previous studies and associated research showed that there was little consistency in how either emerging technologies or Army functions were represented either internationally or domestically in the available literature [Dexter]. In order to develop such a stable, generic, well defined and internally consistent language of communication over the long term, previous work in both technology classifications and military classifications [Dexter] were used as the foundations to develop a classification framework context specific to the Army. Additional constraints were that it would apply across all 5 lines of operation ${ }^{1}$ in all Army activities and stances.

For the classification of the emerging technologies, it was found that terminology was required which was capability based and not enabling discipline or technology based. Enabling technologies often cut across many capability areas and were broad in nature, for example, nanotechnologies. Additionally, the actual specific technologies themselves evolve over time as they trend from emerging to everyday technologies. If the enabling or specific technology area terms are used as the means of classification, then as terminology, and technology types evolve, then the classification system itself is also constantly changing making tracking of the terminology used over time difficult. In addition, the definitions of the terminology must also be clear and evolved over time. The convergence of technologies to produce unforeseen developments is also difficult to classify unless the application of the unforeseen technology is used as its application/s are readily assessed and easily classified into capability based technology areas. Using the well-defined capability technology areas, specific technologies of interest are classified by a "tagging" process where their application or use is categorized according to the technology area/s they apply to. In a similar way the technologies of interest are tagged with Army functions of impact. This tagging of the specific technologies of interest is maintained within the overall analytical and data storage process and these "tags" of classification can be adapted and evolved over time as required without loss of history.

The foundations of classifications for both the generic army functions and emerging technologies [Dexter] were then refined using a modified Delphi-like process [Dexter]. The foundation for the generic army functions implemented was adapted and refined from the core skills proposed by Curtis \& Dortmans [Curtis 2004]. The modified Delphi like process was conducted in two rounds (where the changes made were not considered to be significant to either the terminology used or the structure of the framework) using a distributed anonymous online survey. The results of each survey were analysed using thematic analysis [Pincombe, Boyatzis 1998]. The first survey asked participants from across the Land domain (with backgrounds in both technologies and Army functions), to assess the classifications and their definitions, capture areas missed, and provide better or new terminology. They were also asked to assess the consistency of the terminology across the categories for both the technologies and the Generic Army functions. The second survey presented a refined classification framework with new definitions based on feedback from the first round and asked similar questions based on preference, consistency and necessary critical changes. This process of refinement resulted in the two-sided classification framework presented below where each side is listed along with its definition. This framework allows segmentation of the complex space in an analytical and well considered manner which provides further information as the technologies are "tagged" with multiple technology areas and Army functions showing their potential impact across the space.

Below is the two-sided classification framework refined from previous work [Dexter, Curtis 2004] using the process described above.

\section{Generic Army Functions}

Engagement: includes: deliver appropriate \& targeted firepower to disable or restrict the enemy and their ability to operate; and deliver/provide capability to support and engage with local populations.

Information Collection: gain useful information on the operational environment (in its broad context including the population) including fighting for information.

Sustainment: includes: maintain operational momentum by distributing resources and maintain all capability across all lines and types of operation; preparedness; training and education; workforce management; modernisation; health; maintenance; and field services.

Communication: includes: manage and transfer information securely; share useful information and enhance appreciation of the situation across the spectrum of operations; and inform, shape perceptions, attitudes, behaviour and understanding of populations.

\footnotetext{
${ }^{1}$ The 5 lines of operation of the Australian Army are: joint land combat, population protection, public information, population support and indigenous capacity building [Adaptive Campaigning 09]
} 
Dexter, Assessing the impact of emerging technologies on the Australian Army

Protection: includes: reduce effect of potential hazards to conduct operations (including on population); and provide immediate security to population to allow re-establishment of law and order.

Movement: includes: ability to relocate units and assets/capability to conduct the spectrum of operations; and capacity to relocate populations and supporting capability in support of broader operations.

Command: provision of necessary requirements to make good and appropriate decisions during operations allowing the advantage to be gained and allowing the battlespace to be shaped.

\section{Emerging Technology Areas}

Power Technologies: includes all those technologies with the capacity to provide (or contribute to the capacity to provide) power and energy (including storage and distribution) to systems.

Information Technologies: broad term covering both contemporary devices and software which enables users to create, access, store, manipulate and manage information.

Robotics \& Autonomous Systems: technologies and algorithms allowing machines to operate remotely with a spectrum of independence from human control, ranging from total dependency on the human to complete self sufficiency.

Weapon Technologies \& Methods: all technologies and methods which contribute to and form part of systems or processes which have the potential to act as a weapon (includes lethal, less than lethal, cyber-attack, electronic warfare, information warfare, psychological, biological attack etc.)

Sensor Technologies: all forms of sensor technologies including position, targeting, navigation, detection, chemical, biological etc.

Health Technologies: all aspects relating to health and wellbeing of Army personnel and those they are protecting on operations.

Transportation Technologies: includes the technologies and principles (and those which contribute to) Army's transportation needs across the spectrum of operations.

Materials \& Manufacturing Technologies: all materials which impact or give advantage to Army (or an enemy) as well as developments in manufacturing methods.

Protection Technologies: includes materials, methods, weapons for protection of Army capability and those they are supporting on operations.

Table 1 presents the two-sided classification framework as a simple visual representation in matrix form. This matrix represents the study space for the domain which is then segmented into sectors of technology area and generic army function based on a similar approach [Pincombe]. Each of these sectors represents an area which can be studied in detail in a more manageable way. This segmentation of the study space allowed a preliminary assessment to be undertaken which visually shows where the technology areas are anticipated to have an impact on the generic army functions (this assessment is to be further refined in subsequent analyses). In the matrix shown in Table 1, the segments are shaded such that black represents a high likelihood of impact of the technology area on the Army function, grey indicates some likelihood of impact and the white areas are unlikely to have impact. In this way the very large complex space of both emerging technologies and army functions, can be reduced in scope to focus on areas where there is likely to be impact, and analytical resources can be focused there in the first instance. It is intended to explore the entire space commencing with the black and grey followed by the white areas as there may be impact in those white areas that is not readily seen until the analysis is undertaken. This representation also allows a clear way to engage with stakeholders ensuring all the elements are visible and not obscured by too much information.

Another benefit of using a generic, stable and consistent set of terms for the army functions, is that over time Army uses different classifications for their functions. For example, there are currently Battlefield Operating Systems (BOS), Fundamental Inputs to Capability (FICS), Key Functions of Capability [LWD1 2008] and Core Land Integration Primary Systems (CLIPS) [Army Objective Force 2030 2011] used by Army, to name a few. With a consistent set of well-defined generic army functions, the terminology remains static preventing confusion or loss of data, and these can be readily mapped to other classifications of interest. Table 2 shows an example of mapping from the Generic Army Functions to the BOS by comparing definitions. When comparing definitions it was found that the BOS terminology varies from broad general 
Dexter, Assessing the impact of emerging technologies on the Australian Army

terms (e.g. information dominance and influence) to specific capability based terms such as Ground Based Air Defence $(\mathrm{GBAD})^{2}$.

Table 1 The two-sided classification framework presented in matrix form with the study space segmented into technology/function areas. The segments are shaded to indicate anticipated impact areas from darkest (highest likely impact) to lightest (lowest likely impact).

\begin{tabular}{|c|c|c|c|c|c|c|c|c|c|}
\hline $\begin{array}{ll} & \\
\text { Generic } & \text { Army } \\
\text { Functions } & \end{array}$ & 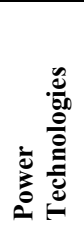 & 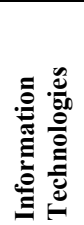 & 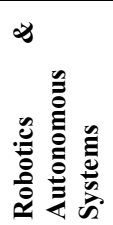 & 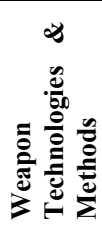 & 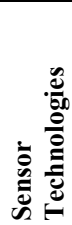 & 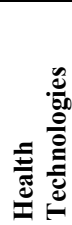 & 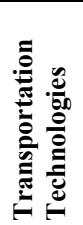 & 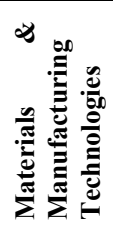 & 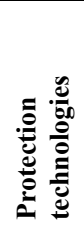 \\
\hline Engagement & & & & & & & & & \\
\hline Information Coll & & & & & & & & & \\
\hline Sustainment & & & & & & & & & \\
\hline Communication & & & & & & & & & \\
\hline Protection & & & & & & & & & \\
\hline Movement & & & & & & & & & \\
\hline Command & & & & & & & & & \\
\hline
\end{tabular}

Table 2 The BOS mapped to the Generic Army Functions

\begin{tabular}{|l|l|}
\hline Generic Army Function & BOS \\
\hline Engagement & Maneouvre, offensive support, info dominance \& influence \\
\hline Information Collection & ISR, info dominance \& influence \\
\hline Sustainment & CSS \\
\hline Communication & C2, info dominance \& influence \\
\hline Protection & GBAD, mobility \& Survivability \\
\hline Movement & Maneouvre, mobility \& Survivability \\
\hline Command & C2 \\
\hline
\end{tabular}

\section{TECHNIQUES}

The two-sided classification framework and TOWS [Coyle 2004] based impact analysis are two key features of a larger schema (figure 1) where overlapping techniques are used to provide both bottom up (impacts of emerging technologies on Army functions) and top down (gaps in Army future plans requiring technological solutions) outputs. These form part of an ongoing process of evolution and adaption of the data, techniques and methods used over time. In this way, the overall process becomes more robust and better at learning from previous outcomes to provide better analytical outcomes and future strategies.

In order to populate the content of the technology areas in the matrix, the technologies of interest are collated (and categorised) using overlapping methods in order to ensure the greatest scope of the problem space is captured. These methods include input from the Joint Innovation Centre, literature research of emerging technology domains, and survey (Subject Matter Expert (SME)) input from DSTO \& Army.

Across the classification framework, there are 63 segments of generic army functions and emerging technology combinations where one or more TOWS assessments of plausible technology impacts are

\footnotetext{
${ }^{2}$ It is noted that the BOS have a purpose and with that in mind they would not be a representation of overall
} Army roles, though they are sometimes considered to be a standard classification for Army. 
undertaken. Even though the likelihood of impacts may not be expected in some areas, as discussed above, each block will need to be considered in turn in order to ensure that plausible outcomes of interest are not overlooked. Table 1 shows the preliminary assessment of areas of likely impact. There are still considerable segments to cover even if only the segments of high impact were covered. In order to ensure the limited available resources are targeted effectively and to ensure Army receives reports on the areas of greatest interest to them first, Army staff further prioritise the matrix segments in order to determine the order of study of each segment. This priority order of study is mapped to the likely areas of impact to determine the order of segment analysis through the matrix.

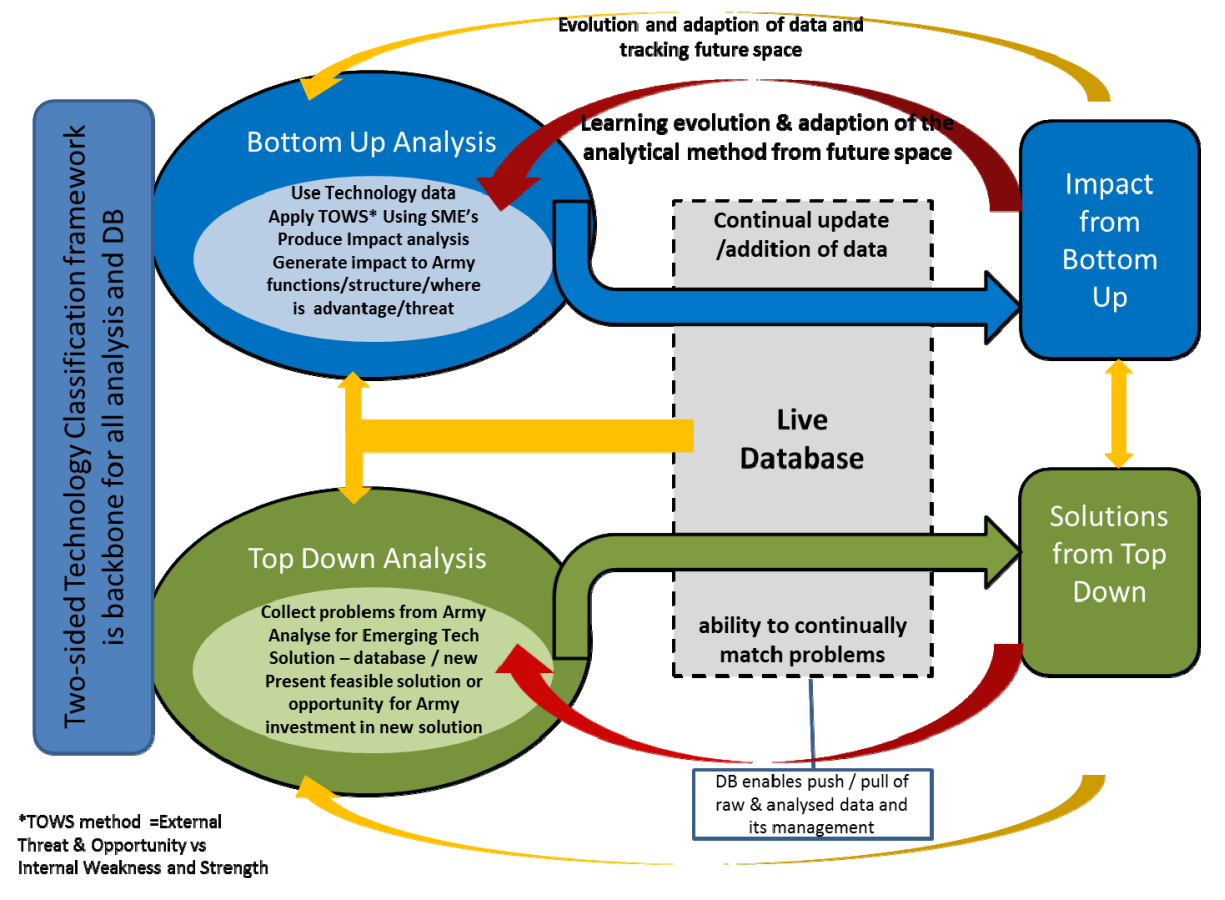

Figure 1 Overall schema for undertaking studies on emerging technologies for the Australian Army

Each segment of technology area and generic army function is detailed (in turn) and SME's engaged to undertake the plausible impact analyses using the qualitative technique known as TOWS. The TOWS technique ${ }^{3}$ compares external Threats and Opportunities to the internal Weaknesses and Strengths of the problem space to arrive at a set of actions to protect against threats and allow opportunities to be taken advantage of. The application of TOWS here in assessing plausible impacts readily allows actions and strategies to be identified for the future Army [Coyle 2004, Weihrich 1982]. TOWS was chosen as the preferred method due to its design focusing on the external Threats \& Opportunities and internal Weaknesses $\&$ Strengths to the system which are all important items for consideration in this problem. Additionally, the systematic development of strategies and outcomes from these elements ensures each focus area is considered in turn in a structured manner allowing application of the 'so what' principle. Its successful use in a previous study of Army emerging technologies provided additional evidence that it would provide the necessary required outputs [Pincombe].

For this project, the definition of external for the TOWS Threats and Opportunities includes all those things which are external to and might impact the Army including the technology, opposition or other actors, strategic or other environment considerations, social implications, allies etc. The definition of internal for the TOWS Weaknesses and Strengths includes all those things which are internal to and might impact the Army including technology, Army legacy and cultural systems, structure, etc. The structure of a TOWS matrix is based on a $3 \times 3$ matrix with the external Threats \& Opportunities elements articulated in the first row and the

\footnotetext{
${ }^{3}$ TOWS derives from the SWOT technique but the changes to its design and focus on external versus internal leading to outcomes and actions is recognised as being both more efficient and avoiding many of the pitfalls from SWOT [Coyle 2004, Weihrich 1982].
} 
internal Weaknesses \& Strengths articulated in the first column. At the matrix segments which comprise the intersection of the TOWS combinations, the outcomes/strategies and impacts of those combinations are articulated. Table 3 shows how this is implemented for the example given. It is possible in the TOWS analysis that some TOWS elements are critical enough that they form an uncombined strategy on their own in the matrix.

\section{IMPACT ANALYSIS}

The TOWS method was used to generate the assessments of plausible impacts of future technologies on the generic army functions. Technology SME's were used to ensure the technology space was scoped in detail and to provide detailed information where required on specific technologies during the process of the TOWS analysis. The development of the TOWS analysis occurs in several stages. Initially, the analytical team constructs a TOWS matrix by populating the components based on research and technology SME input. In the next stage, local SME's (across the Land Domain) are consulted to further populate and refine the TOWS matrix based on the initial development. This enables broader functional contexts to be considered as well as capturing a greater scope of data. Finally, this TOWS matrix is then presented to Army function SMEs (within Army) to enable the impacts - outcomes - strategies to be determined with a clear Army focus. These impacts - outcomes - strategies are then considered and scoped in further detail to produce plausible scenarios and possible strategies based on plausible impacts and are reported back to Army for strategic planning guidance.

Presented in table 3 is an example of a TOWS matrix where the impact of Power technologies is considered against the Movement generic army function. In this example, the data is illustrative of that from the completed analysis to enable its publication in an unclassified domain.

\section{Table 3 Illustrative TOWS assessing the plausible impacts of power technologies on the movement function}

Impact technology: Power Technologies - Includes all technologies with the capacity to provide (or contribute to the capacity to provide) power and energy (including storage and distribution) to systems.

Army Function: Movement - ability to relocate units and assets/capability to conduct the spectrum of operations; and capacity to relocate populations and supporting capability in support of broader operations.

\begin{tabular}{|c|c|c|}
\hline & $\begin{array}{l}\text { Threats (external) } \\
\text { T1. Power source mismatches } \\
\text { a. between us and local country } \\
\text { b. between us and allies } \\
\text { T2. Different systems may have different } \\
\text { transition times to new systems } \\
\text { T3. Fully autonomous systems may not be } \\
\text { as responsive as a human operated vehicle }\end{array}$ & $\begin{array}{l}\text { Opportunities (external) } \\
\text { O1. Cheap batteries and clean energy } \\
\text { systems results in cheaper and lighter } \\
\text { transportation technologies } \\
\text { O2. Logistics will be simplified } \\
\text { O3. Smaller acoustic signature } \\
\text { O4. Space/suborbital travel may become } \\
\text { cheaper and more achievable }\end{array}$ \\
\hline $\begin{array}{l}\text { Weaknesses (internal) } \\
\text { W1. Renewable energy production may } \\
\text { not be as efficient in each environment } \\
\text { W2. Lack of trained engineers to repair the } \\
\text { new systems } \\
\text { W3. Costly to transform/adapt vehicles to } \\
\text { new power systems } \\
\text { W4. Safety and longevity profiles of some } \\
\text { of the new systems have not been } \\
\text { established }\end{array}$ & $\begin{array}{l}\text { a. Maximise the flexibility of the power } \\
\text { system employed so that a vehicle is able } \\
\text { to operate in a wide range of environments. } \\
\text { Select power generation systems which are } \\
\text { functional in a wide range of } \\
\text { environments. Fit vehicles with more than } \\
\text { one mode of power usage (W1,T1,W4) } \\
\text { b. Due to the costs and effort required to } \\
\text { transition to new power systems, various } \\
\text { countries may have differing transition } \\
\text { timelines. It will be important to align the } \\
\text { Army's transition with our allies transition } \\
\text { timelines to ensure we are able to draw } \\
\text { upon their re-fuelling stations during } \\
\text { operations (W3, T1). } \\
\text { c. Build up knowledge and skill sets of } \\
\text { engineers, so that they are proficient in } \\
\text { repairing both the old and new vehicles } \\
\text { (W2, T2, T3) }\end{array}$ & $\begin{array}{l}\text { a. Though some of the technical and safety } \\
\text { details of the new power systems are } \\
\text { unknown, Army has had experience } \\
\text { establishing risk profiles for the } \\
\text { employment in new capabilities. Also, the } \\
\text { Army can draw upon operations research } \\
\text { to establish how best to employ the new } \\
\text { systems in a selection of scenarios (W1, } \\
\text { W4, O1) } \\
\text { b. The initial investment in transforming } \\
\text { vehicles to new modular power systems } \\
\text { may be costly, however modular systems } \\
\text { are less expensive to maintain and repair. } \\
\text { (W3, O1) } \\
\text { c. New innovations such as apps and } \\
\text { online training guides may guide engineers } \\
\text { in the repair process and ease the transition } \\
\text { (W2, W3, O3) }\end{array}$ \\
\hline
\end{tabular}




\begin{tabular}{|c|c|c|}
\hline $\begin{array}{l}\text { Strength (internal) } \\
\text { S1. Renewable energy is an independent } \\
\text { source of energy } \\
\text { S2. Renewable energy has a smaller } \\
\text { environmental impact \& footprint } \\
\text { S3. Powerful and light batteries are a key } \\
\text { enabler for other technologies: autonomous } \\
\text { systems, sensors, I.T. \& manufacturing }\end{array}$ & $\begin{array}{l}\text { a. Many countries, including our allies, are } \\
\text { transitioning to more sustainable fuels due } \\
\text { to their smaller environmental impact and } \\
\text { their cost, and it will be vital for us to align } \\
\text { our transition with our allies' transition } \\
\text { timelines. This will ensure that we can } \\
\text { source fuel from the allies during } \\
\text { operations, if need be (S2, T1) } \\
\text { b. Though developments in autonomous } \\
\text { systems provide many opportunities, they } \\
\text { will also carry some challenges (S3, T3) } \\
\text { (further explored in the Autonomous- } \\
\text { Movement TOWS) }\end{array}$ & $\begin{array}{l}\text { a. Given that many of the current systems, } \\
\text { across a range of areas, will become } \\
\text { lighter, Army will have an opportunity to } \\
\text { re-define what is deployed during } \\
\text { operations (S3, O1, O2, O3) } \\
\text { b. Lighter more powerful energy sources } \\
\text { will lighten the load for soldiers and } \\
\text { improve their mobility in the field. (S3, } \\
\text { O4) } \\
\text { c. Having access to long-lasting batteries, } \\
\text { printable solar systems and wireless power } \\
\text { systems will mean the Army can travel to } \\
\text { places which were previously inaccessible } \\
\text { to vehicles (S1, O2). This will change the } \\
\text { way Army assesses the feasibility of } \\
\text { certain operations }\end{array}$ \\
\hline
\end{tabular}

\section{CONCLUSION}

This paper has discussed the method used to provide useful plausible impact of emerging technology data to Army. It has presented a two-sided classification framework which underpins a larger overall process of emerging technology study for the Australian Army. This classification framework was then used as the backdrop to demonstrate how plausible impacts of emerging technologies on generic army functions are assessed using the TOWS method. The output from this process is primarily focused on providing Army with guidance for strategic and future planning however, the applicability of the overall program of work is much broader. This includes access to a live database providing up to date snapshots of analytical data, providing auditable emerging technology inputs and possible impacts to Simulation \& Wargaming, evolution of the question and analysis process, tracking of trends and technology changes, mapping of the generic Army functions to other Army function classifications, and developing scenarios for analysis.

\section{REFERENCES}

Adaptive Campaigning '09 - Army's Future Land Operating Concept, Directorate of Army Research and Analysis, 2009 http://army.gov.au/Ourfuture/DARA/ /media/Files/Our\%20future/DARA\%20Publications/ACFLOC_2012\%20main.ashx

Boyatzis, R.E., Transforming Qualitative Information. 1998: Sage Publications

Coyle, G., Practical Strategy: Structured Tools and Techniques. 2004, Harlow: Pearson Education Ltd

Curtis, N.J. \& P. J. Dortmans, A dynmaic conceptual model to explore technology-based perturbations to a complex system: the land force, Asia Pacific Journal of Operations Research, 2004, 21(4), 463-485

Dexter , P. A Two-Sided Contextual Technology Classification Framework for the Australian Army submission to Technological Forecasting \& Social Change, in preparation

LWD 1 - The Fundamentals of Land warfare, The Australian Army, 2008

Pincombe, B \& Dexter P., The Possible Effects of Potential Key Technological Developments on the Force Structure of the Australian Army in 2040, submitted for publication

The Army Objective Force Primer 2030, Land Warfare Development Centre, 2011, http://www.army.gov.au/Ourfuture/ /media/Files/Our\%20future/Publications/Army\%20AOF\%202030.ashx

Weihrich, H., The TOWS Matrix - A tool for situational analysis. Long Range Planning, 1982. 15(2): 54-66 